
\title{
IMPACT OF DIFFERENT STEEPING TIME AND WATER TEMPERATURE ON TEA LIQUOR
}

\author{
Murugesan Palanivel ${ }^{1}$, Venkateswaran Gopal ${ }^{2}$, Kalimuthupandian Subbaiah Thevar ${ }^{3}$, Shanmugaselvan \\ Veilumuthu $^{4}$ \\ E-Mail Id: mpm_sun@yahoo.co.in \\ UPASI-Tea Research Foundation, Regional Centre, Coonoor, Nilgiris, Tamil Nadu, India \\ UPASI-Tea Research Foundation, Tea Research Institute, Valaparai, Coimbatore, Tamil Nadu, India
}

\begin{abstract}
The steeping time and water temperature is very important in determining ideal taste of tea. The optimum water temperature and steeping time only gives good quality tea liquor. Lesser steeping time and lower water temperature adversely affects the liquor quality. Higher steeping time also result in low quality. Medium steeping time with higher water temperature gives good liquor quality, with higher theaflavin, thearubugin and total liquor colour.
\end{abstract}

Key Words: Theaflavin, Thearubigin, liquor, colour, time and temperature

\section{INTRODUCTION}

Tea is the most widely consumed beverage throughout the world and India is among the top producers of high quality black CTC tea [2]. The color and brightness are the critical quality attributes which are few yard stick for fixing rank and price in tea trading. Black tea is fermented tea and during fermentation an enzymatic oxidation of tea polyphenols, especially tea catechins takes place which lead to formation of polyphenolic pigment compounds such as theaflavins (TFs) and thearubigins (TRs). Usually black tea liquor colour attributes determined by colorimetric methods does not always corresponds to the tea tasters evaluation and rankings [1]. The methods of preparing the beverage vary throughout the world. Steeping tea in hot water is at above $85^{\circ} \mathrm{C}$ for 5 to $8 \mathrm{~min}$. However, it has been shown that the concentration of biochemical content (Theaflavin, Thearubigin, etc) in a cup of tea is dependent on steeping conditions namely, water temperature and steeping duration [3].

Steeping conditions such as time and temperature are critical factors for extraction of catechins or theaflavins from tea. The traditional method of making a cup of tea in some countries is to place loose leaves directly into a pot and pour boiling water over the leaves. After a couple of minutes the leaves are usually removed and the brew is consumed. The extractable phytochemicals associated with the health benefits and their levels depend on the method of tea preparation for its consumption [4]. Many parameters may affect the sensory and nutritional quality of tea brew such as maturity of the leaves, processing parameters and expected sensory quality. It has been reported that both time and temperature of tea infusion have pronounced effects on the extraction of tea biochemical content [5]. The present study aimed at the optimization of the bio chemical content by solubilization in water to concentrate them. The objective of the present study was to determine the effects of temperature $\left(75,85\right.$ and $\left.95^{\circ} \mathrm{C}\right)$ and steeping duration $(5,8,10,12$ and $15 \mathrm{~min})$ on the solubilization of tea biochemical content.

\section{MATERIALS AND METHOD}

\subsection{Materials}

IBMK (Iso Butyl Methyl Ketone), Butanol, Disodium hydrogen Phosphate, Sodium Carbonate, Folin reagent, Sulphuric acid, Gallic acid and catechins.

\subsection{Method}

The study was carried out using fannings grade CTC (Curl,Tear,Crush) blak tea. Two percent tea was steeped for varying duration and varying water temperature. The steeped tea brew was analysed for liquor parameters, total polyphenols, total catechins and total soluble solids (TSS). The study was repeated thrice. Water temperature was varying from $75,85,95^{\circ} \mathrm{C}$. Steeping temperature above $95^{\circ} \mathrm{C}$ was not possible as the experiment was conducted at an elevation of 1760 above MSL. Steeping time varied from 5 to $15 \mathrm{~min}$.

\section{PROCEDURE}

\subsection{Analysis}

Laboratory analysis was carried out in UPASI Tea Research Foundation, Regional centre, Coonoor, The Nilgiris, Tamilnadu, India, a NABL (National Accreditation Board for Testing and Calibration Laboratories) accredited DOI Number: 10.30780/IJTRS.V3.I1.2018.005

Www.ijtrs.com

www.ijtrs.org 


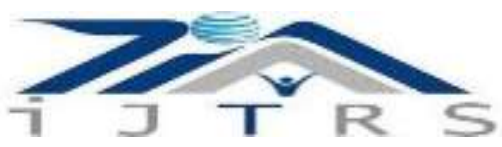

\section{International Journal of Technical Research \& Science}

laboratory for chemical testing as per ISO/IEC 17025:2005. All analytical results were calculated on dry matter basis (DMC).

\subsection{Dry Matter Content (DMC)}

The procedure for determining dry matter content is given below. Weight the empty bottle (A g), Bottle with $5 \mathrm{~g}$ tea sample (B g) and Bottle with $5 \mathrm{~g}$ tea sample after 16 hours drying $(\mathrm{C} \mathrm{g})$.

$\mathrm{DMC} \%=\mathrm{C}-\mathrm{A} * 100$

$$
\text { B-A }
$$

\subsection{Quality Analysis - Liquor}

$2 \mathrm{~g}$ of made tea was added to $100 \mathrm{ml}$ freshly boiled water and steeped for $10 \mathrm{~min}$ at a temperature 75 to $95^{\circ} \mathrm{C}$ kept in water bath. Brewed tea filtered through cotton and liquor was taken for analysis. $25 \mathrm{ml}$ of tea liquor was shaken with $25 \mathrm{ml}$ of IBMK in separating funnel and allowed to separate to organic and aqueous layer (A). $10 \mathrm{ml}$ of aqueous layer was shaken with $10 \mathrm{ml}$ of Butanol and allowed to form organic (B) and aqueous (D) layer. $10 \mathrm{ml}$ of IBMK layer solution was shaken with $10 \mathrm{ml}$ of $2.5 \%$ disodium hydrogen phosphate solution and allowed to separate to organic (C) and aqueous layer. $1 \mathrm{ml}$ of each A, B, C, D layer was pipetted out in $9 \mathrm{ml}$ of $45 \%$ ethanol in test tube. $1 \mathrm{ml}$ of steeped tea was pipetted out in $9 \mathrm{ml}$ of distilled water in test tube (E). The optical density (OD) of all the solutions was determined in UV spectrophotometer (GBC 918. Australia). OD of solution E at $460 \mathrm{~nm}$ represents total liquor colour of tea (TLC). OD at $380 \mathrm{~nm}$ of A, B, C, D solutions were determined. A, B and C represent Thearubigins (TR), C represents Theaflavins (TF).Concentration of TF, TR, HPS and TLC was calculated from the absorbance values as given below. The calculation factors include molar extension coefficient and dilution [6], [7].

$$
\begin{gathered}
\text { TF\% }=\text { C } * 4.313 * 100 \\
\text { DMC } \\
\text { HPS } \%=\text { D*13.643*100 }
\end{gathered}
$$

$\mathrm{DMC}$

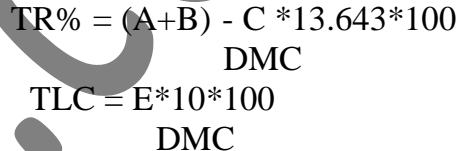

\subsection{Total Catechins}

$1 \mathrm{ml}$ of $2 \%$ steeped tea was pipette out into $50 \mathrm{ml}$ standard measuring flask (SMF) and made up to mark. 2 ml of aliquot was pipette out in a boiling test tube and $6.5 \mathrm{ml}$ of $1 \%$ vanaline solution (70\% Sulphuric acid) was added. $1.5 \mathrm{ml}$ of water was added to this solution and kept for $30 \mathrm{~min}$ for development of colour. After colour developments optical density was determined at $500 \mathrm{~nm}$ in spectrophotometer (GBC 918, Australia). The same procedure adopted for catechins 10, 20, 30, 40, 50 ppm standards.

\section{Total Catechins $\mathrm{mg} / \mathrm{kg}=\mathrm{Graph}$ reading $* 50$}

\subsection{Total Polyphenols}

$1 \mathrm{ml}$ of $2 \%$ steeped tea was diluted to $100 \mathrm{ml}$ in SMF. $1 \mathrm{ml}$ of this solution was pipetted out in a test tube, $5 \mathrm{ml}$ of Folin-Ciocalteu reagent (diluted 1:10) added to polyphenol extract solution. After $5 \mathrm{~min}, 4 \mathrm{ml}$ of $7.5 \%$ sodium carbonate solution was added and allowed to remain for $1 \mathrm{~h}$ for colour development. After colour development, OD was determined at $765 \mathrm{~nm}$ in spectrophotometer (GBC 918, Australia). The same process was done for standard Gallic acid 10, 20, 30, 40 and 50 ppm solutions

Total polyphenols $\mathrm{mg} / \mathrm{kg}=\mathrm{Graph}$ reading*100

\subsection{Total soluble solids (TSS)}

Weight* $1 *$ DMC

$25 \mathrm{ml}$ of $2 \%$ steeped tea was pipette out to pre weighed dish (W1) and evaporated in boiling water bath to dryness and kept in oven at $100^{\circ} \mathrm{C}$ for half an hour. The dish was cooled in dessicator and weighed (W2).

\section{RESULTS AND DISCUSSION}

$$
\begin{gathered}
\mathrm{TSS} \%=\mathrm{W} 2-\mathrm{W} 1 * 100 * 100 * 100 \\
2 * 25 * \mathrm{DMC}
\end{gathered}
$$

Theaflavin content contributed positively toward valuations [8], [9].This study clearly indicates that increase in temperature for brewing tea increased the elution capacity. Biochemical compounds and water extract are increased. Elution of biochemical compounds and water extract was increased at $95^{\circ} \mathrm{C}$ (Table. 1). Tea is a source of natural colour [10]. The characteristic colour of black tea is generated during its manufacturing process. During this process, the colourless catechins which are abundant in fresh leaves are oxidized both enzymatically and chemically to give two major groups of pigments, theaflavins and thearubigins. The colour of liquor increases upto 12 min steeping time but slightly decreases when steeping time is $15 \mathrm{~min}$. Color and strength are related to thearubigin contents. One 


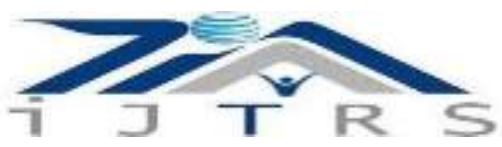

\section{International Journal of Technical Research \& Science}

of the components of enzymatic oxidation is theaflavins and it is known that during fermentation the theaflavins reach a peak after which they are believed to undergo further oxidation to produce thearubigins [9]. The analytical results show increasing thearubigin levels at high temperature up to $12 \mathrm{~min}$ (Table. 1). The formation of thearubigin linked to quality characteristics of black tea [11]. When fresh tea leaves are crushed at the initial stage, the four major catechins are enzymatically oxidized and the resulting quinones undergo complex chemical changes. Composition of the oxidation products of tea catechins is extremely complex (Tanaka and koun, 2003). Polyphenols and catechins solubilisation increased by increasing temperature and time was maximum at $95^{\circ} \mathrm{C}$ for 15 mins steeping (Table-1).

The total soluble components of tea are responsible for the taste, aroma and strength [12].The elution of solids at temperature at $75^{\circ} \mathrm{C}$ was very low. The results indicate that at 5 and $10 \mathrm{~min}$. steeping time the level of soluble solids was low. At 8, 10 and 12min steeping time the level of total soluble solids high under different temperature, 5 min steeping time had low steeping capacity. 8, 10 and $12 \mathrm{~min}$ had high steeping capacity. Higher steeping time did not retaining the biochemical compounds. TSS increased with increased steeping time (Table. 1).

\section{CONCLUSION}

Tea biochemical compounds are temperature sensitive. Hence when steeping at higher temperature the biochemical compounds are lost. Total soluble solids are higher with higher temperature and longer steeping time. Solubilisation of tea increases with high temperature and steeping duration but biochemical compounds like theflavin and thearubigin are degrading. Liquor quality is good when steeped above $85^{\circ} \mathrm{C}$ for 10 min as evidenced from biochemical analysis.

\section{ACKNOWLEDGEMENTS}

The authors are thankful to Dr. B. Radhakrishnan, Director, UPASI Tea Research Foundation, Tea Research Institute, Valparai, Tamilnadu, India for permitting to carried out the trails and analysis and Mr. K. G. Udayabhanu, Asst Director, Mr. M. G. Sathish, Engineer UPASI Tea Research Foundation, Regional centre, Coonoor, The Nilgiris, Tamilnadu, India for constant guidance, moral support and encouragement.

\section{REFERENCES}

[1] Amit Laddi, Shashi Sharma, Amod Kumar and Neelam Rup Prakash. Influence on Color Attributes of Freshly Brewed Tea with Time due to Variations in Temperature Conditions. International Journal of Computer Applications, Volume 34- No.7, 2011.

[2] Suteerapataranon.S, Butsoongnern.J, Punturat.P, Jorpalit.W and Chuleeporn Thanomsilp.C. Caffeine in Chiang Rai tea infusions: Effects of tea variety, type, leaf form, and infusion conditions. Food Chemistry 114, 13351338, 2009.

[3] Hajiaghaalipour.F, Sanusi.J, and Kanthimathi.M.S. Temperature and Time of Steeping Affect the Antioxidant Properties of White, Green, and Black Tea Infusions. Journal of food science, vol. 81,Nr 1, 2015.

[4] Fernando.C.D and Soysa.P. Extraction Kinetics of phytochemicals and antioxidant activity during black tea (Camellia sinensis L.) brewing. Nutrition Journal 14:74, 2015.

[5] Saklar.S, Ertas.E, Ozdemir.I.S and Karadeniz.B. Effects of different brewing conditions on catechin content and sensory acceptance in Turkish green tea infusions. Journal of Food Science and Technology. 52(10):6639664,2015

[6] Roberts, E. A. H \& Smith, R. F. Phenolic substances of manufactured tea. II Spectrophotometric valuation of tea liquors. Journal of the Science of Food and Agriculture, 14, 689-700, 1963.

[7] Tea board. Scientific publication on Tea chemistry, No. 8,1995.

[8] Liang. Y and Yu.Y. Effect of $\mathrm{pH}$ on cream particle formation and solid extraction yield of black tea. Food Chemistry 74, 155-160,2001.

[9] Ansari Hassanpour asil.M, Rabiei. B and Dadashpour.A. Impacts of flushing and fermentation times on the quality of black tea. Genetika, vol. 43, No. 3,537 -548, 2001.

[10] Baruah.S, Bordoloi. I, A.K, Gogoi. R. C, M. K. Gogoi. M. K. and Hazarika. M. An integrated approach to the extraction of natural tea color, flavor and evaluation of antioxidant properties of tea. Two and a Bud 59(2):126-129, 2012.

[11] Tanaka.T and kouno. I.Oxidation of tea catechins: chemical structures and reaction mechanism. Food Science and Technology Research., 9 (2), 128-133, 2003.

[12] Someswararao.C, Srivastav. P.P and Das.H. Quality of Black Teas in Indian market. African Journal of Agricultural Research Vol. 8(5), pp. 491-494,15, 2013. 
I T $\mathrm{R} S$ International Journal of Technical Research \& Science

Table-1 Impact of Different Steeping Time and Water Temperature on Tea Liquor Biochemical Parameters

\begin{tabular}{|c|c|c|c|c|c|c|c|c|}
\hline $\begin{array}{l}\text { Temp } \\
{ }^{\circ} \mathrm{C}\end{array}$ & $\begin{array}{l}\text { Time } \\
(\min )\end{array}$ & TF\% & TR\% & HPS\% & TLC & $\begin{array}{l}\text { TPP } \\
\mathrm{mg} / \mathrm{kg}\end{array}$ & $\begin{array}{l}\mathrm{TC} \\
\mathrm{mg} / \mathrm{kg}\end{array}$ & $\begin{array}{l}\text { Total soluble } \\
\text { solids \% }\end{array}$ \\
\hline \multirow{5}{*}{75} & 5 & 0.93 & 9.00 & 8.59 & 3.44 & 2145 & 1667 & 35.03 \\
\hline & 8 & 1.02 & 9.78 & 9.08 & 3.72 & 2315 & 1678 & 36.56 \\
\hline & 10 & 1.08 & 9.78 & 9.19 & 3.90 & 2393 & 1768 & 35.70 \\
\hline & 12 & 1.11 & 9.92 & 9.28 & 3.90 & 2419 & 1918 & 37.82 \\
\hline & 15 & 1.08 & 10.34 & 9.28 & 3.88 & 2381 & 1918 & 38.09 \\
\hline \multirow{5}{*}{85} & 5 & 0.97 & 10.09 & 8.57 & 3.55 & 2154 & 1719 & \\
\hline & 8 & 1.12 & 10.68 & 9.27 & 4.07 & 2457 & 1937 & \\
\hline & 10 & 1.17 & 10.37 & 9.32 & 3.99 & 2457 & & \\
\hline & 12 & 1.13 & 10.39 & 9.35 & 4.09 & 2441 & & \\
\hline & 15 & 1.18 & 10.67 & 9.49 & 4.11 & 2390 & & 39.02 \\
\hline \multirow{4}{*}{95} & 5 & 1.04 & 9.60 & 8.76 & 3.74 & 225 & & 35.20 \\
\hline & 8 & 1.18 & 10.60 & 9.19 & 4.04 & 2517 & 1768 & 36.44 \\
\hline & 10 & 1.32 & 10.97 & 9.47 & 4.33 & 2587 & 2062 & 38.69 \\
\hline & 12 & 1.27 & 10.95 & 9.56 & 4,40 & 2517 & 2024 & 38.39 \\
\hline
\end{tabular}

